\title{
Multivariate analysis of genetic diversity in Phytophthora pod rot resistant exotic cocoa germplasm
}

\author{
S.A. Veeresh, J.S. Minimol*, B. Suma, P.S. Panchami and K.S. Shilpa \\ Cocoa Research Centre, Kerala Agricultural University, Vellanikkara, Thrissur-68 065, Kerala, India
}

(Manuscript Received: 23-03-2020, Revised: 25-09-2020, Accepted: 04-11-2020)

\begin{abstract}
The current research work was carried out to evaluate the genetic diversity associated with 30 cocoa accessions resistant to Phytophthora. The cluster analysis and principal component analysis evaluated the genetic variability among the different genotypes. The highest number of genotypes were observed in cluster III (8) when qualitative traits were considered. In quantitative cluster analysis, most of the genotypes were placed in separate clusters due to high variability in the germplasm. Principal component (PC) analysis showed that the first three PCs with more than one Eigen-value contributed to 79.9 per cent of variability for different traits. When qualitative and quantitative characters were considered along with resistant reaction, clusters with genotypes highly resistant to Phytophthora pod rot were observed. Hybridization programme involving these resistant hybrids belonging to diverse clusters will result in high yielding hybrids with ample resistance.
\end{abstract}

Keywords: Cluster analysis, cocoa, genetic diversity, pod rot, principal component analysis

\section{Introduction}

Cocoa (Theobroma cacao L.) is a perennial tropical crop mainly found in the rainforests and thrives well in tropical climatic areas. It belongs to the Malvaceae family. At present, cocoa is cultivated in an area of 78,000 hectares in India with a production of around 18,920 metric tonnes (DCCD, 2017). It is grown in all South Indian states.

Among the major cocoa diseases identified, Phytophthora black pod is the one which affects cocoa production extremely (Opoku et al., 2000). The shady conditions prevailing in the cropping systems coupled with congenial climatic conditions during South-West monsoon (June-October) provides a favourable condition for the development and spread of Phytophthora. Since the disease incidence is prevalent during the rainy season, the fungicidal spray could control this disease only to a limited extent due to washing off of the fungicides from plant surface which ultimately leads to heavy economic loss (Anderson and Guest, 1990; Guest and Grant, 1991). Hence, the use of resistant varieties is recommended for effective and ecofriendly control.

The identification of genetic stock for Phytophthora resistance is fundamental for parental selection for future breeding programmes. A fruitful breeding program includes comprehensive knowledge and thorough understanding of variability present within the available resource. It permits choosing parents of diverse genetic makeup. Subsequently, clustering of Phytophthora resistant accessions based on their morphological traits is mandatory to guarantee genetic divergence before utilizing it in the breeding programmes.

Multivariate statistics have been used in recent years to determine the genetic variations between different genotypes. Principal component analysis (PCA) and cluster analysis are employed to work out similarities and differences between different genotypes regarding multiple traits under examination (Jian et al., 2006). The cluster analysis

*Corresponding Author: minimoljs@gmail.com 
is an effective tool for evaluating family relationships (Mellingers, 1972). The advantage of using PCA over cluster analysis is that it is possible to assign each germplasm line to one group. It also highlights the significance of a major contributor to overall diversity at each axis of differentiation (Mohammadi, 2002). The goal of the current study is to evaluate the genetic diversity among the exotic accessions reported to be resistant to Phytophthora by using cluster analysis and PCA tools so that it will form the basis for identifying genetic stocks for the resistant breeding programme.

\section{Materials and methods}

\section{Experimental site and material used}

The present evaluation was conducted at the Cocoa Research Centre, Kerala Agricultural University (KAU), Thrissur, Kerala. Exotic cocoa accessions which were reported to be resistant to Phytophthora pod rot disease in other countries were introduced through the University of Reading, U.K. cocoa germplasm hub. They were field planted during 2009 and are now in the steady bearing stage. Thirty accessions that expressed field resistance to Phytophthora pod rot were selected for the study (Table 1). Further resistance was confirmed by pod inoculation method as suggested by Iwaro et al. (2000). The genotypes were classified as highly resistant ( 0 to $15 \%$ ), resistant $(15.1$ to $25 \%$ ), moderately resistant (25.1 to $50 \%)$, moderately susceptible (50.1 to $75 \%$ ) and susceptible (more than $75 \%$ ) based on pod area infection percentage. All the agronomical and cultivation practices such as fertilizer application, weeding and irrigation were adopted as per the package of practices recommended by KAU.

\section{Measurement of qualitative and quantitative traits}

The data on qualitative and quantitative morphological characters were recorded on flowers, leaves and pods collected from exotic accessions of cocoa using the descriptor given by Bekele and Butler (2000) was used for genetic diversity analysis. Qualitative characteristics were carried out by recording the flush, pedicel, sepal and petal colours, the shape of pod, the form of pod apex, the form of pod basal constriction, the colour of the
Table 1. List of cocoa genotypes used in the present study

\begin{tabular}{|c|c|}
\hline Sl. No. & Accessions \\
\hline A1 & CRU 12 \\
\hline A2 & ICS 29 \\
\hline A3 & ICS 41 \\
\hline A4 & MO 109 \\
\hline A5 & GDL 7 \\
\hline A6 & PA 194 \\
\hline A7 & SIAL 339 \\
\hline A 8 & TARS 31 \\
\hline A9 & GU 261/P \\
\hline A 10 & LZ 28 \\
\hline A11 & NA 149 \\
\hline A12 & MATINA 1/7 \\
\hline A13 & PA 303 \\
\hline A14 & PNG 87 \\
\hline A15 & PA 156 \\
\hline A16 & LX 43 \\
\hline A17 & POUND 4/B \\
\hline A18 & PNG 418 \\
\hline A19 & JA 10/12 \\
\hline A20 & F 303 \\
\hline A 21 & Т 85/799 \\
\hline A 22 & DOM 14 \\
\hline A 23 & PNG 250 \\
\hline A24 & PNG 336 \\
\hline A 25 & IMC 20 \\
\hline A26 & EET 397 \\
\hline A 27 & ICS 75 \\
\hline A28 & DOM 25 \\
\hline A29 & POUND 18 \\
\hline $\mathrm{A} 30$ & POUND 16/A \\
\hline
\end{tabular}

unripe pod, the pod rugosity and the colour of the cocoa bean. The quantitative floral characters, bean characters and yield characters viz., flower diameter $(\mathrm{cm})$, pedicel length $(\mathrm{cm})$, sepal length and breadth $(\mathrm{cm})$, petal breadth $(\mathrm{cm})$, length of staminode and stamen $(\mathrm{mm})$, ovary length, breadth and length of style $(\mathrm{mm})$, pod weight $(\mathrm{g})$, ridge thickness $(\mathrm{cm})$, furrow thickness $(\mathrm{cm})$, pod length and breadth $(\mathrm{cm})$, number of beans/pod, the total weight of beans per pod $(\mathrm{g})$, wet weight of single bean $(\mathrm{g})$, dry bean length, width and thickness ( $\mathrm{mm})$, single dry bean weight $(\mathrm{g})$ yield (number of pods per tree per year), 
Table 2. Descriptive statistics of exotic germplasm of cocoa

\begin{tabular}{|c|c|c|c|c|c|}
\hline Traits & Mean & Minimum & Maximum & $\begin{array}{c}\text { Coefficient } \\
\text { of variation }(\%)\end{array}$ & F ratio \\
\hline Flower diameter $(\mathrm{cm})$ & 1.19 & 0.89 & 1.47 & 11.94 & $5.558 * *$ \\
\hline Pedicel length (cm) & 1.01 & 0.82 & 1.83 & 11.45 & $13.112 *$ \\
\hline Sepal length (cm) & 0.63 & 0.52 & 0.74 & 8.59 & $5.069 *$ \\
\hline Sepal breadth (cm) & 0.16 & 0.10 & 0.21 & 15.60 & $9.549 *$ \\
\hline Petal length (cm) & 0.76 & 0.65 & 0.89 & 10.89 & $3.383^{*}$ \\
\hline Petal breadth $(\mathrm{cm})$ & 0.19 & 0.12 & 0.20 & 10.82 & $6.408^{*}$ \\
\hline Length of staminode $(\mathrm{cm})$ & 0.56 & 0.47 & 0.68 & 8.80 & $7.073 *$ \\
\hline Length of stamen (cm) & 0.19 & 0.16 & 0.28 & 14.81 & $3.076^{*}$ \\
\hline Ovary length (cm) & 0.14 & 0.11 & 0.22 & 14.83 & $2.859 *$ \\
\hline Ovary breadth (cm) & 0.10 & 0.09 & 0.13 & 7.83 & $1.603 * *$ \\
\hline Length of style (cm) & 0.18 & 0.15 & 0.25 & 11.27 & $2.29 *$ \\
\hline Pod weight (g) & 440 & 125 & 750 & 8.77 & $77.191 *$ \\
\hline Ridge thickness $(\mathrm{cm})$ & 1.33 & 0.63 & 2.10 & 14.81 & $15.984 *$ \\
\hline Furrow thickness $(\mathrm{cm})$ & 0.89 & 0.38 & 1.36 & 17.94 & $9.590 *$ \\
\hline Pod length (cm) & 7.94 & 5.66 & 10.12 & 12.62 & $6.244^{*}$ \\
\hline Pod breadth $(\mathrm{cm})$ & 15.69 & 11.20 & 24.20 & 13.83 & $7.310^{*}$ \\
\hline No of beans pod ${ }^{-1}$ & 42.94 & 20.80 & 60.60 & 9.97 & $21.266^{*}$ \\
\hline Total wet bean weight pod $^{-1}(\mathrm{~g})$ & 113.85 & 39.14 & 189.32 & 14.18 & $25.822 *$ \\
\hline Wet weight of single bean (g) & 2.51 & 1.20 & 4.04 & 7.52 & $65.742 *$ \\
\hline Dry bean length $(\mathrm{mm})$ & 19.76 & 22.98 & 13.01 & 9.62 & $7.332 *$ \\
\hline Dry bean thickness (mm) & 7.05 & 4.67 & 9.20 & 9.15 & $12.465^{*}$ \\
\hline Dry bean width $(\mathrm{mm})$ & 11.71 & 9.04 & 13.66 & 11.58 & $3.526^{*}$ \\
\hline Single dry bean weight (g) & 1.00 & 0.48 & 1.45 & 9.84 & $26.997 *$ \\
\hline Pod value (g) & 42.88 & 17.04 & 69.17 & 8.77 & $37.96 * *$ \\
\hline Conversion index & 0.39 & 0.20 & 0.72 & 13.83 & $26.44 * *$ \\
\hline No. of pods tree ${ }^{-1}$ year ${ }^{-1}$ & 51.26 & 34.00 & 75.00 & 12.25 & $2.59 * *$ \\
\hline Efficiency index & 10.74 & 5.22 & 18.27 & 17.94 & $34.95 * *$ \\
\hline Dry matter recovery $(\%)$ & 41.55 & 25.12 & 73.28 & 11.29 & $11.60 * *$ \\
\hline
\end{tabular}

*Significant at $0.05 \% \quad * *$ Significant at $0.01 \%$

pod value $(\mathrm{g})$, pod index, efficiency index, conversion index and dry matter recovery (\%) were also recorded. The observations were reported from an average of five fruits picked at random from each accession. Descriptive statistics on quantitative characters are depicted in Table 2.

\section{Data analysis}

Using statistical software NTSYSpc v.2.02 package (Applied Biostatistics), the data were subjected to multivariate analysis using $\mathrm{D}^{2}$ statistics by Mahalanobsis (1936) and Rao (1952). Clustering was carried out based on Jaccard's similarity matrix, and a dendrogram was constructed by Agglomerative method (Day and Edelsbrunner, 1984). The principal component analysis was performed using NTSYSpc, and PC plot was generated by MINITAB12.MPJ.

\section{Results and discussion}

\section{Cluster analysis based on qualitative traits}

Genetic improvement needs a strong basis for genetic diversity. The information about germplasm diversity and genetic relatedness among the elite breeding materials is a major component in plant breeding (Mukhtar et al., 2002). The existence of 


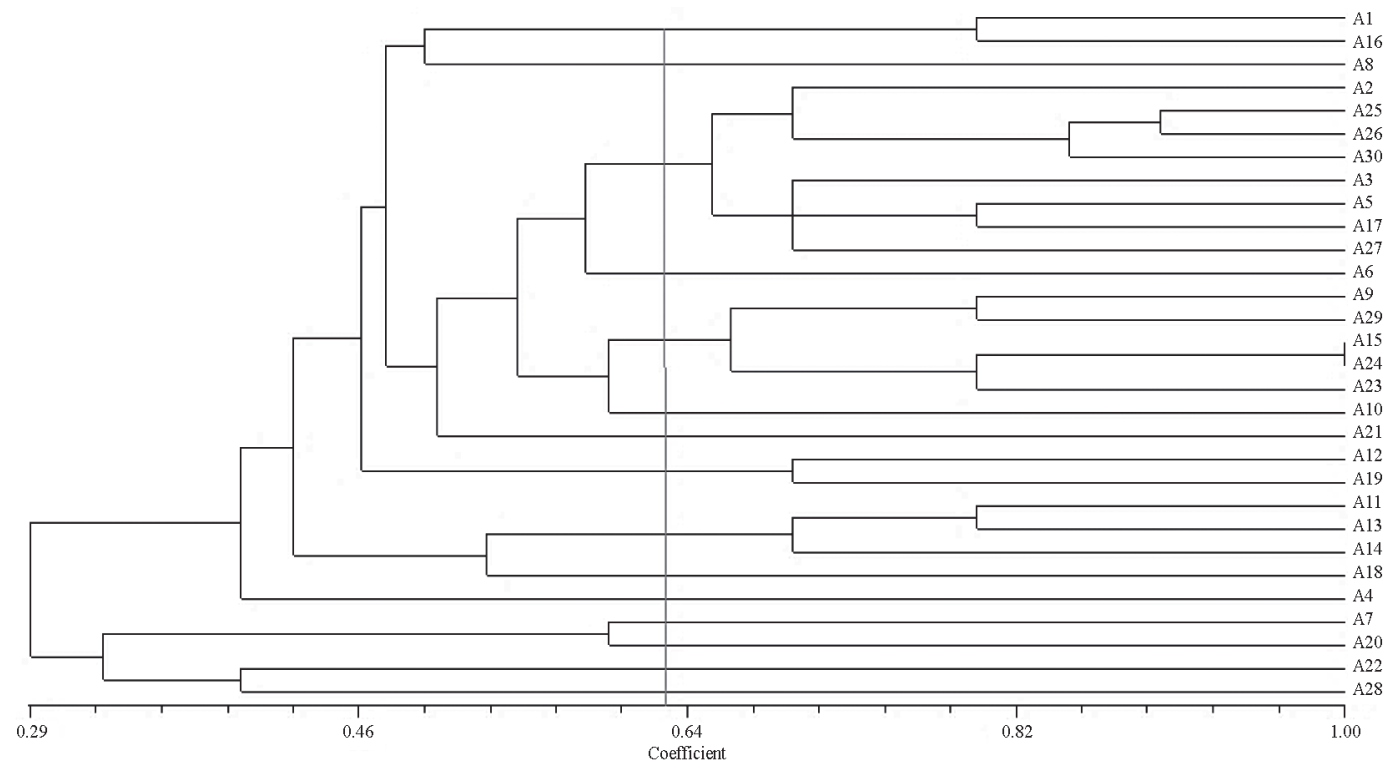

Fig. 1. Dendrogram showing clustering of qualitative traits in cocoa genotypes

genetic divergence among the thirty exotic accessions of cocoa cultivars was examined by employing $\mathrm{D}^{2}$ statistic. The cluster analysis of qualitative traits was carried out based on Jaccard's similarity coefficient by unweighted paired group approach using the arithmetic average (UPGMA). The dendrogram drawn out of UPGMA is presented in Figure 1.

Thirty exotic accessions used for the current study were grouped into 15 clusters with 60 per cent similarity coefficient. Table 3 provides the accessions contained in each cluster when it was grouped based on qualitative character. Cluster III with eight genotypes formed the largest of the fifteen clusters. The accessions CRU 12 and LX 43 were grouped in Cluster I. They shared identical characters viz., reddish pedicel, greenish-red flush colour and the lack of reddish pigments over the pod and dark purple bean colour. The accessions GU 261/P, PA 156, PN G 250, PNG 336 and POUND 18 were grouped under Cluster V based on presence of similar characters such as the absence of anthocyanin pigments on the pod, green pedicel colour, acute pod apex and absence of pod base. Cluster VIII consists of two accessions MATINA $1 / 7$ and JA 10/12. These two accessions were similar with respect to cream coloured sepal, absence of anthocyanin pigmentation, Cundeamore pod shape and acute pod apex. The three accessions NA 149,
PA 303 and PNG 87 gathered under Cluster IX shared common features such as green pod colour, absence of pod base, slight pod rugosity and dark purple bean colour. All remaining clusters consisted of one member each, and they were distinct from the other clusters. Lachenaud et al. (1999) conducted a study to find out floral descriptors for characterizing the variability in cocoa and found that floral descriptors are a powerful tool to discriminate between the genotypes. The outcome of the present study was in line with their findings.

\section{Cluster analysis based on quantitative characters}

The exotic genotypes showed wide variability with respect to quantitative characters and thus resulted in distinct groups at 50 per cent similarity. To arrive at a conclusion, clustering was done at 25 per cent similarity based on Jaccard's similarity coefficient. Thirty accessions were grouped into 20 clusters, and the result is represented as a dendrogram in Figure 2.

Cluster wise classification of accessions was given in Table 4. Cluster II was the biggest cluster among all the clusters, and it included accessions TARS 31, PNG 418 and PNG 87. These accessions were similar with respect to quantitative characters like sepal length, petal breadth and length of the stamen. Cluster IV, V, VI, VIII, X, XI, XII, XIV 
Table 3. Clustering of genotypes based on qualitative characters in cocoa

\begin{tabular}{|c|c|c|c|}
\hline Cluster No. & $\begin{array}{c}\text { No. of } \\
\text { genotypes }\end{array}$ & Genotypes & Similar characters shared between accessions \\
\hline Cluster I & 2 & CRU 12, LX 43 & $\begin{array}{l}\text { Reddish pedicel colour, greenish red flush colour, } \\
\text { absence of reddish pigments over pod and dark } \\
\text { purple bean colour }\end{array}$ \\
\hline Cluster II & 1 & TARS31 & \\
\hline Cluster III & 8 & $\begin{array}{l}\text { ICS 29, IMC 20, EET397, } \\
\text { POUND 16/A,GDL 7, ICS 41, }\end{array}$ & \\
\hline & & POUND 4/B, ICS 75 & Green pod colour \\
\hline Cluster IV & 1 & PA194 & \\
\hline Cluster V & 5 & $\begin{array}{l}\text { GU 261/P, POUND 18, PA 156, } \\
\text { PNG 336,PNG } 250\end{array}$ & $\begin{array}{l}\text { Absence of anthocyanin pigments on pod, green } \\
\text { pedicel colour, acute pod apex and absence of pod base }\end{array}$ \\
\hline Cluster VI & 1 & LZ 28 & \\
\hline Cluster VII & 1 & T $85 / 799$ & \\
\hline Cluster VIII & 2 & MATINA 1/7, JA 10/12 & $\begin{array}{l}\text { Cream colour sepal, absence of anthocyanin } \\
\text { pigmentation, Cundeamore pod shape and acute pod apex }\end{array}$ \\
\hline Cluster IX & 3 & NA 149, PA 303,PN G87 & $\begin{array}{l}\text { Green pod colour, absence of pod base, slight pod } \\
\text { rugosity and dark purple bean colour }\end{array}$ \\
\hline Cluster X & 1 & PNG 418 & \\
\hline Cluster XI & 1 & MO 109 & \\
\hline Cluster XII & 1 & SIAL 339 & \\
\hline Cluster XIII & 1 & F 303 & \\
\hline Cluster XIV & 1 & DOM 14 & \\
\hline Cluster XV & 1 & DOM 25 & \\
\hline
\end{tabular}

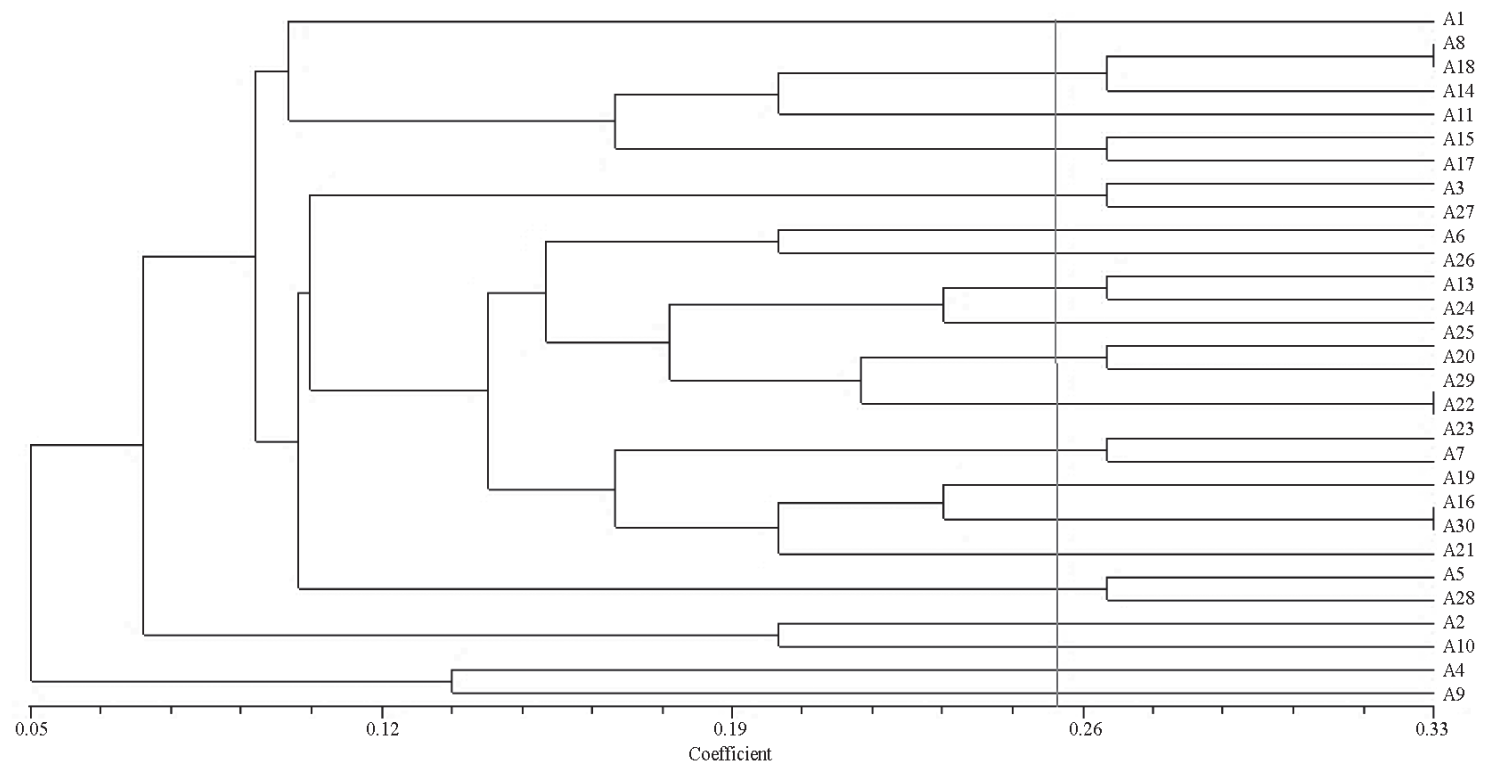

Fig. 2. Dendrogram showing clustering of quantitative traits in cocoa genotypes 
Table 4. Clustering of genotypes based on quantitative characters in cocoa

\begin{tabular}{lcl}
\hline $\begin{array}{l}\text { Cluster } \\
\text { No. }\end{array}$ & $\begin{array}{c}\text { No. of } \\
\text { genotypes }\end{array}$ & Genotypes \\
\hline Cluster I & 1 & CRU 12 \\
Cluster II & 3 & TARS 31, PNG 418, PNG 87 \\
Cluster III & 1 & NA 149 \\
Cluster IV & 2 & PA 156, POUND 4/B \\
Cluster V & 2 & ICS 41, ICS 75 \\
Cluster VI & 1 & PA 194 \\
Cluster VII & 1 & EET 397 \\
Cluster VIII & 2 & PA 303, PNG 336 \\
Cluster IX & 1 & IMC 20 \\
Cluster X & 2 & F 303, POUND 18 \\
Cluster XI & 2 & DOM 14, PNG 250 \\
Cluster XII & 2 & SIAL 339, JA10/12 \\
Cluster XIII & 1 & MATINA 1/7 \\
Cluster XIV & 2 & LX 43, POUND 16/A \\
Cluster XV & 1 & T 85/799 \\
Cluster XVI & 2 & GDL 7, DOM 25 \\
Cluster XVII & 1 & ICS 29 \\
Cluster XVIII & 1 & LZ 28 \\
Cluster XIX & 1 & MO 109 \\
Cluster XX & 1 & GU 261/P \\
\hline
\end{tabular}

and XVI consist of two accessions each, and each cluster is distinct from other clusters. All remaining clusters comprised of one member each. Several studies used divergent analysis to determine the variability among the genotypes in a population or between populations (Ram and Panwar, 1970; Engels, 1986; Asna, 2013; Ajmal, 2016). Jagadev et al. (1991) reported that greater emphasis should be placed on the characters contributing the maximum to the divergence to decide further selection. When there is more diversity among parents, the chance of getting elevated heterosis is greater (Zaman et al., 2005). Therefore, crossing between genotypes belonging to different clusters may lead to high heterosis that could be exploited in the improvement of cocoa.

\section{Reactions of different genotypes in each cluster to Phytophthora pod rot resistance}

The response of genotypes included in each cluster (qualitative and qualitative) against Phytophthora pod rot disease is represented in Table 5 and Table 6 , respectively. The results revealed that characters (qualitative and quantitative) have not much contribution to disease resistance in cocoa. The genotypes present in cluster V (qualitative) were all highly resistant to pod rot, and the familiar characters shared between these includes the absence of anthocyanin pigments on the pod, green pedicel colour, acute pod apex and absence of pod base. These characters might be having a positive influence on conferring disease resistance in cocoa. Similarly, in cluster IX, two genotypes were moderately resistant, and one was highly resistant to the black pod. This might be due to the absence of the pod base and slight pod rugosity in these two accessions. Thresh et al. (1988) and Iwaro et al. (1997) reported that reason behind the resistance of pod rot in cocoa accessions was due to smooth surface of the pod (absence of rugosity) with the absence of basal constriction.

Table 5. Eigen values and cumulative variability in different PCs for economic attributes in cocoa genotypes

\begin{tabular}{lrrrrr}
\hline Variable & PC1 & PC2 & PC3 & PC4 & PC5 \\
\hline Number of pod tree ${ }^{-1}$ year $^{-1}$ & -0.15 & 0.65 & 0.14 & -0.569 & -0.443 \\
Pod value (g) & 0.56 & 0.31 & -0.11 & 0.118 & 0.044 \\
Pod index & -0.50 & -0.42 & 0.24 & -0.152 & -0.172 \\
Efficiency index & -0.36 & 0.40 & 0.16 & 0.790 & -0.233 \\
Conversion index & 0.44 & -0.35 & 0.15 & 0.123 & -0.790 \\
Dry matter recovery (\%) & 0.27 & 0.06 & 0.91 & -0.008 & 0.360 \\
Eigen value & 2.44 & 1.41 & 1.00 & 0.634 & 0.497 \\
Per cent variance & 40.8 & 23.7 & 15.5 & 10.6 & 8.3 \\
Cumulative variance (\%) & 40.8 & 64.5 & 79.9 & & 90.5 \\
\hline
\end{tabular}


Table 6. Reaction of different genotypes in each qualitative cluster to Phytophthora pod rot resistance

\begin{tabular}{|c|c|c|c|}
\hline \multirow{2}{*}{$\begin{array}{l}\text { Cluster No. } \\
\text { Cluster I }\end{array}$} & Genotypes & \multirow{2}{*}{$\begin{array}{c}\begin{array}{c}\text { Percentage } \\
\text { of infection }\end{array} \\
5.8\end{array}$} & \multirow{2}{*}{$\begin{array}{l}\text { Class } \\
\text { Highly resistant }\end{array}$} \\
\hline & CRU 12 & & \\
\hline & b. $\quad$ LX 43 & 5.2 & Highly resistant \\
\hline Cluster II & a. TARS 31 & 51.9 & Moderately susceptible \\
\hline \multirow[t]{8}{*}{ Cluster III } & ICS 29 & 28.6 & Moderately resistant \\
\hline & b. IMC 20 & 0.0 & Highly resistant \\
\hline & c. $\quad$ EET 397 & 25.4 & Moderately resistant \\
\hline & d. POUND 16/A & 2.9 & Highly resistant \\
\hline & e. $\quad$ GD L7 & 4.5 & Highly resistant \\
\hline & f. $\quad$ ICS 41 & 0.0 & Highly resistant \\
\hline & POUND 4/B & 7.6 & Highly resistant \\
\hline & h. $\quad$ ICS 75 & 5.6 & Highly resistant \\
\hline Cluster IV & a. PA 194 & 15.1 & Resistant \\
\hline \multirow[t]{5}{*}{ Cluster V } & GU 261/P & 3.4 & Highly resistant \\
\hline & b. POUND 18 & 2.2 & Highly resistant \\
\hline & c. PA 156 & 1.5 & Highly resistant \\
\hline & d. $\quad$ PNG 336 & 0.0 & Highly resistant \\
\hline & e. $\quad$ PNG 250 & 0.0 & Highly resistant \\
\hline Cluster VI & a. $\quad$ LZ 28 & 21.7 & Resistant \\
\hline Cluster VII & a. $\quad$ T 85/799 & 13.2 & Highly resistant \\
\hline \multirow[t]{2}{*}{ Cluster VIII } & a. MATINA $1 / 7$ & 31.8 & Moderately resistant \\
\hline & b. JA $10 / 12$ & 0.7 & Highly resistant \\
\hline \multirow[t]{3}{*}{ Cluster IX } & a. $\quad$ NA 149 & 10.7 & Highly resistant \\
\hline & b. $\quad$ PA 303 & 40.0 & Moderately resistant \\
\hline & c. $\quad$ PNG 87 & 26.9 & Moderately resistant \\
\hline Cluster X & a. $\quad$ PNG 418 & 14.4 & Highly resistant \\
\hline Cluster XI & a. $\quad$ MO 109 & 1.2 & Highly resistant \\
\hline Cluster XII & a. $\quad$ SIAL 339 & 0.0 & Highly resistant \\
\hline Cluster XIII & a. $\quad$ F 303 & 45.3 & Moderately resistant \\
\hline Cluster XIV & a. $\quad$ DOM 14 & 0.3 & Highly resistant \\
\hline Cluster XV & a. DOM 25 & 7.3 & Highly resistant \\
\hline
\end{tabular}

\section{Principal component analysis (PCA)}

Principal component analysis (PCA) clearly shows the characteristics within the genotype collections, which are the key source of variation. The first principle component accounts for as much variability in the data, and the remaining variability is accounted for by each successive component (Hotelling, 1933; Mardia, 1971). In the present study, the principal component analysis was carried out using five economic variables. Table 7 explains the Eigen values, variability (\%) and cumulative variance $(\%)$. 
Genetic diversity in Phytophthora pod rot resistant cocoa germplasm

Table 7. Reaction of different genotypes in each quantitative cluster to Phytophthora pod rot resistance

\begin{tabular}{|c|c|c|c|}
\hline Cluster No. & Genotypes & Percentage of infection & Class \\
\hline Cluster I & a. CRU 12 & 5.8 & Highly resistant \\
\hline \multirow[t]{3}{*}{ Cluster II } & a. TARS 31 & 51.9 & Moderately susceptible \\
\hline & b. PNG 418 & 14.4 & Highly resistant \\
\hline & c. PNG 87 & 26.9 & Moderately resistant \\
\hline Cluster III & a. NA 149 & 10.7 & Highly resistant \\
\hline \multirow[t]{2}{*}{ Cluster IV } & a. PA 156 & 1.5 & Highly resistant \\
\hline & b. POUND 4/B & 7.6 & Highly resistant \\
\hline \multirow[t]{2}{*}{ Cluster V } & a. ICS 41 & 0.0 & Highly resistant \\
\hline & b. ICS 75 & 5.6 & Highly resistant \\
\hline Cluster VI & a. PA 194 & 15.1 & Resistant \\
\hline Cluster VII & a. EET 397 & 25.4 & Moderately resistant \\
\hline \multirow[t]{2}{*}{ Cluster VIII } & a. PA 303 & 40.0 & Moderately resistant \\
\hline & b. PNG 336 & 0.0 & Highly resistant \\
\hline Cluster IX & a. IMC 20 & 0.0 & Highly resistant \\
\hline \multirow[t]{2}{*}{ Cluster X } & a. F 303 & 45.3 & Moderately resistant \\
\hline & b. POUND 18 & 2.2 & Highly resistant \\
\hline \multirow[t]{2}{*}{ Cluster XI } & a. DOM 14 & 0.3 & Highly resistant \\
\hline & b. PNG 250 & 0.0 & Highly resistant \\
\hline \multirow[t]{2}{*}{ Cluster XII } & a. SIAL 339 & 0.0 & Highly resistant \\
\hline & b. JA 10/12 & 0.7 & Highly resistant \\
\hline Cluster XIII & a. MATINA 1/7 & 31.8 & Moderately resistant \\
\hline \multirow[t]{2}{*}{ Cluster XIV } & a. LX 43 & 5.2 & Highly resistant \\
\hline & b. POUND16/A & 2.9 & Highly resistant \\
\hline Cluster XV & a. $\mathrm{T} 85 / 799$ & 13.2 & Highly resistant \\
\hline \multirow[t]{2}{*}{ Cluster XVI } & a. GDL 7 & 4.5 & Highly resistant \\
\hline & b. DOM 25 & 7.3 & Highly resistant \\
\hline Cluster XVII & a. ICS 29 & 28.6 & Moderately resistant \\
\hline Cluster XVIII & a. LZ 28 & 21.7 & Resistant \\
\hline Cluster XIX & a. MO 109 & 1.2 & Highly resistant \\
\hline Cluster XX & a. GU 261/P & 3.4 & Highly resistant \\
\hline
\end{tabular}

The PCA revealed that five principal components PC1, PC2, PC3, PC4 and PC5 with Eigen values $2.44,1.41,1.0,1.45,0.634$ and 0.49 respectively have accounted for 98.8 per cent of the overall accumulate variability among the cocoa cultivars. Out of five PCs, the first three principal components PC1, PC2, and PC3, showed Eigen value of $>1$ accounting for 79.9 per cent of variability (Fig. 3). The first principal component (PC1) accounted for 40.8 per cent of the overall 


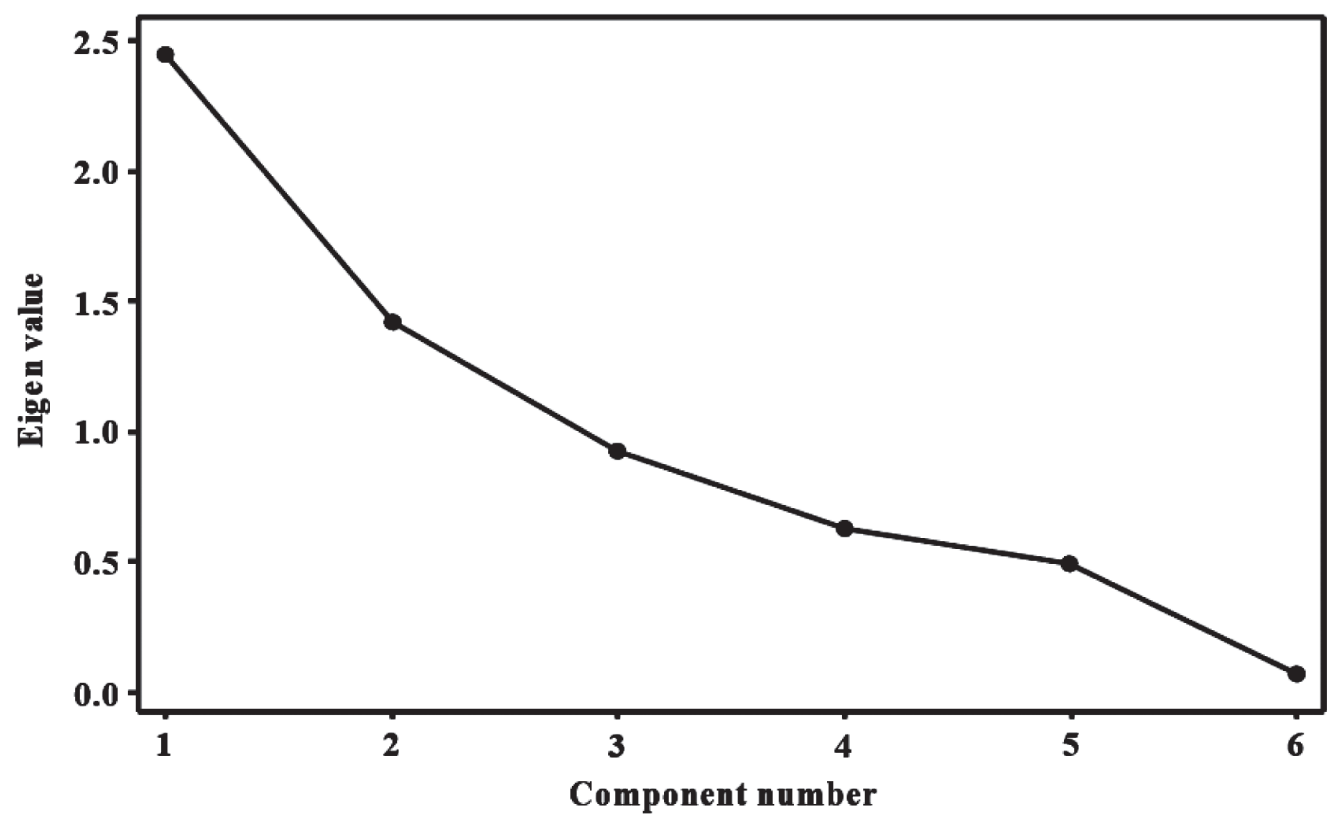

Fig. 3. Screen plot showing Eigen value in response to member principal components for the estimated variables of economic attributes in cocoa

variation and had high contributing factor loadings from pod value (0.56) and conversion index (0.44), thus exposing the correlation of PC1 with these characters. Whereas, pod index $(-0.50)$ had a negative effect on $\mathrm{PC} 1$, thus reducing diversity in PC1. When compared to all other characters, pod value and conversion index contributed to maximum variability. Result of analysis of variance also expressed significant variation for these two characters among the exotic genotypes. Pod value was observed as per the suggestions of Toxopeus and Jacob (1970), and it was calculated by multiplying dry weight per bean with the number of beans per pod, whereas conversion index is defined as the amount of dry bean obtained from a given amount of wet bean weight. Lockwood and Edward (1980) obtained similar result stating that pod value and conversion index showed significant variation among the progenies of a cross between Upper Amazon $\times$ Amelanado, 23.70 per cent of the overall variation was accounted by the second principal component (PC2). The characters highly and positively correlated were the number of pods per tree per year (0.65), efficiency index $(0.40)$ and pod value $(0.31)$. The character, number of pods per tree per year contributed to maximum variation. Result of analysis of variance also revealed a high variability for this character. Lockwood and Edward (1980) also reported in their study that, number of pods per tree per year was contributing to variability in the population. Similarly, Francies (1998) reported that variability among the clonal population in cocoa was contributed by pod value, pod index, efficiency index and conversion index.

The third principal component (PC3) accounted for 15.50 per cent of the total variation, with high contributions from the dry matter recovery (0.91). When compared to the first two components, PC3 contributed very less to variability and majority of variability was expressed due to a single factor dry matter recovery. Contributions by $\mathrm{PC} 4$ and $\mathrm{PC} 5$ were negligible with a total contribution of 10.60 and 8.30 per cent, respectively. Similar studies on PCA on quantitative characters in cocoa by Aikpokpodion (2010) revealed that the first three principal components (PC) contributed to 43.6 per cent of total variation among exotic cocoa accessions.

The loading plot depicting the relationships among various characters based on the first two PCs are presented in Figure 4. The association between two characters in terms of correlation was estimated by the cosine of the angle between their vectors. The loading plot expressed positive correlation 


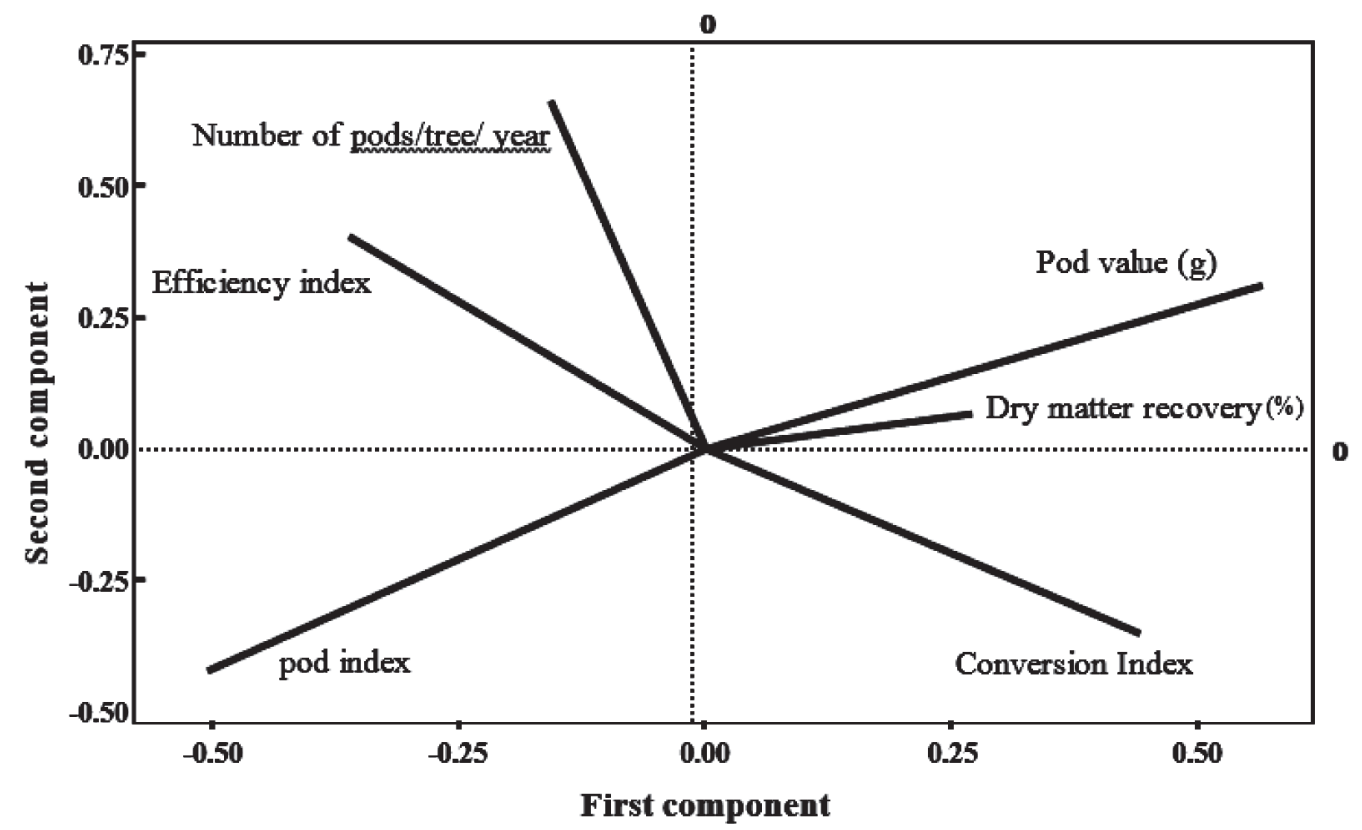

Fig. 4. Biplot of the first two principal components showing relation among economic traits of cocoa

between pod value, dry matter recovery and conversion index; the number of pods per tree per year and efficiency index; pod index and efficiency index, which was revealed by the acute angle between them. A negative correlation of the number of pods per tree per year with pod value, dry matter recovery and conversion index; pod value with pod index and efficiency index; dry matter recovery with pod index and efficiency index; conversion index with pod index and efficiency index was also revealed as the angle between these characters were obtuse.

Pod value, conversion index, efficiency index and the number of pods per tree per year were the major characters contributing to variability in this population, and it is always better to fix these characters as selection criteria (Zachariah, 1983).

\section{Conclusion}

Based on the results of the present investigation, an extensive range of genetic diversity had been experienced in Phytophthora resistant accessions. Emphasis has to be given for characters like pod value, conversion index, no. of pods tree ${ }^{-1}$ year $^{-1}$, efficiency index and dry matter recovery while considering these genotypes for developing genetic stocks. When morphological characters and clusters were compared, it was found that the absence of rugosity contributed to resistance, which has to be confirmed through statistical tools. The resistant genotypes placed in the diverse group can be used as parents in hybridization programme, which will result in high yielders with ample resistance to Phytophthora.

\section{Acknowledgement}

The authors acknowledge Mondelez International and Kerala Agricultural University for financial support.

\section{References}

Aikpokpodion, P.O. 2010. Variation in agro-morphological characteristics of cacao, Theobroma cacao L. in farmers' fields in Nigeria. New Zealand Journal of Crop and Horticultural Science 38: 157-170.

Ajmal, P.M. 2016. Evaluation of selected cocoa (Theobroma cacao L.) hybrids for quality. M.Sc. (Ag) thesis, Kerala Agricultural University, Thrissur, 67p.

Anderson, R.D. and Guest, D.I. 1990. The control of black pod, canker and seedling blight of cocoa caused by Phytophthora palmivora with potassium phosphonate. Australasian Plant Pathology 19: 127-129. 
Asna, A.C .2013. Performance analysis of selected accessions of cocoa (Theobroma cacao L.). M.Sc. (Ag) Thesis, Kerala Agricultural University, Thrissur, 76p.

Bekele, F.L. and Butler, D.R. 2000. Proposed short list of descriptors. In: Working Procedures for Cocoa Germplasm Evaluation and Selection. (Eds.) Eskes, A.B., Engels, J.M.M. and Lass, R.A., Proceedings of the CFC/ ICCO/IPGRI project workshop, Montpellier, France, pp.41-48.

Day, W.H. and Edelsbrunner, H. 1984. Efficient algorithms for agglomerative hierarchical clustering methods. Journal of Classification 1(1):7-24.

DCCD [Directorate of Cashewnut and Cocoa Development]. 2017. AreaProduction and Productivity of Cocoa in India [on-line]. Available: http://dccd.gov.in/content. aspxmid=1072\&tid=1 [06-03-2017].

Engels, J.M.M. 1986. The systematic description of cacao clones and its significance for taxonomy and plant breeding. Ph.D. thesis, Agricultural University of Wageningen, Netherlands, 90p.

Francies, R.M. 1998. Genetic analysis of certain clones, hybrids and inbreds in cocoa. Ph.D. thesis, Kerala Agricultural University, Thrissur, 257p.

Guest, D.I. and Grant, B. 1991.The complex action of phosphonate as antifungal agents. Biological Review 66 (2): 159-187.

Hotelling, H. 1933. Analysis of a complex of statistical variables into principal components. Journal of Educational Psychology 24(6): 417.

Iwaro, A.D., Sreenivasan T.N. and Umaharan, P. 1997. Foliar resistance to Phytophthora palmivora as an indicator of pod resistance in Theobroma cacao. Plant Disease 81: 619-624.

Iwaro, A.D., Sreenivasan T.N., Butler D.R. and Umaharan P. 2000. Rapid screening for Phytophthora pod rot resistance by means of detached pod inoculation. In: Proceedings of the CFC/ICCO/IPGRI Project Workshop. (Eds.) Eskes AB, Engels, J.M.M. and Lass, R.A., IPIGRI, Montpellier, p. 109-113.

Jagadev, P.N., Shamal, K.M. and Lenka, L. 1991. Genetic divergence in rape mustard. Indian Journal of Genetics and Plant Breeding 51: 465-466.

Jian, C.L., Ruili, W.L. and Feng, L.F.W. 2006. Genetic diversity detected by cluster analysis North of Anhui major wheat cultivars. Chinese Agricultural Science Bulletin 11: 031 .

Lachenaud, P., Bonnot, F. and Oliver, G. 1999. Use of floral descriptors to study variability in wild cocoa trees (Theobroma cacao L.) in French Guiana. Genetic Resources and Crop Evolution 46(5): 491-500.

Lockwood, G. and Edward, D.F. 1980. Determination of pod and bean characters in progeny trials with cocoa. Tropical Agriculture 57: 289-300.

Mardia, K.V. 1971. The effect of non-normality on some multivariate tests and robustness to nonnormality in the linear model. Biometrika 58(1): 105-121.

Mellingers, J.S. 1972. Measures of genetic distance studies in genetics. VII University of Texas Publication 27: $145-153$.

Mohammadi, S.A. 2002. Statistical methods in genetics. Paper presented at the $6^{\text {th }}$ International Statistics Conference, University of Tarbiatmodares, Iran, 26-28 August 2002.

Mukhtar, M. S., Rahman M. and Zafar Y. 2002. Assessment of genetic diversity among wheat (Triticum aestivum L.) cultivars from arange of localities across Pakistan using random amplified polymorphic DNA (RAPD) analysis. Euphytica 128: 417.

Opoku, I.Y., Appiah, A.A., Akrofi, A.Y. and Owusu, G.K. 2000. Phytophthora megakarya: a potential threat to the cocoa industry in Ghana. Ghana Journal of Agricultural Science 33(2): 237-248.

Ram, J. and Panwar, D.V.S. 1970. Intraspecific divergence in rice. Journal of Genetics 30: 1-11.

Thresh, J.M., Owusu, G.K., Boamah, A. and Lockwood, G. 1988. Ghanaian cocoa varieties and swollen shoot virus. Crop Protection 7(4): 219-231.

Toxopeus, H. and Jacob, V.J. 1970. Studies on pod and bean values of Theobroma cacao L. in Nigeria- Number of beans per pod, with special reference to the natural pollination process. Journal of Agricultural Science 18: 188-194.

Zachariah, K. 1983. Ascocarp induction in a natural auxotroph of a predatory fungus. Canadian Journal of Botany 61(12): 3262-3266

Zaman, M.R., Paul D.N.R., Kabir, M.S., Mahbub, M.A.A., and Bhuiya, M.A.A. 2005. Assessment of character contribution to the divergence for some rice varieties. Asian Journal of Plant Sciences 4(4): 388-391. 